\title{
125 Jahre Entdeckung der Röntgenstrahlen und den 175. Geburtstag von Wilhelm Conrad Röntgen
}
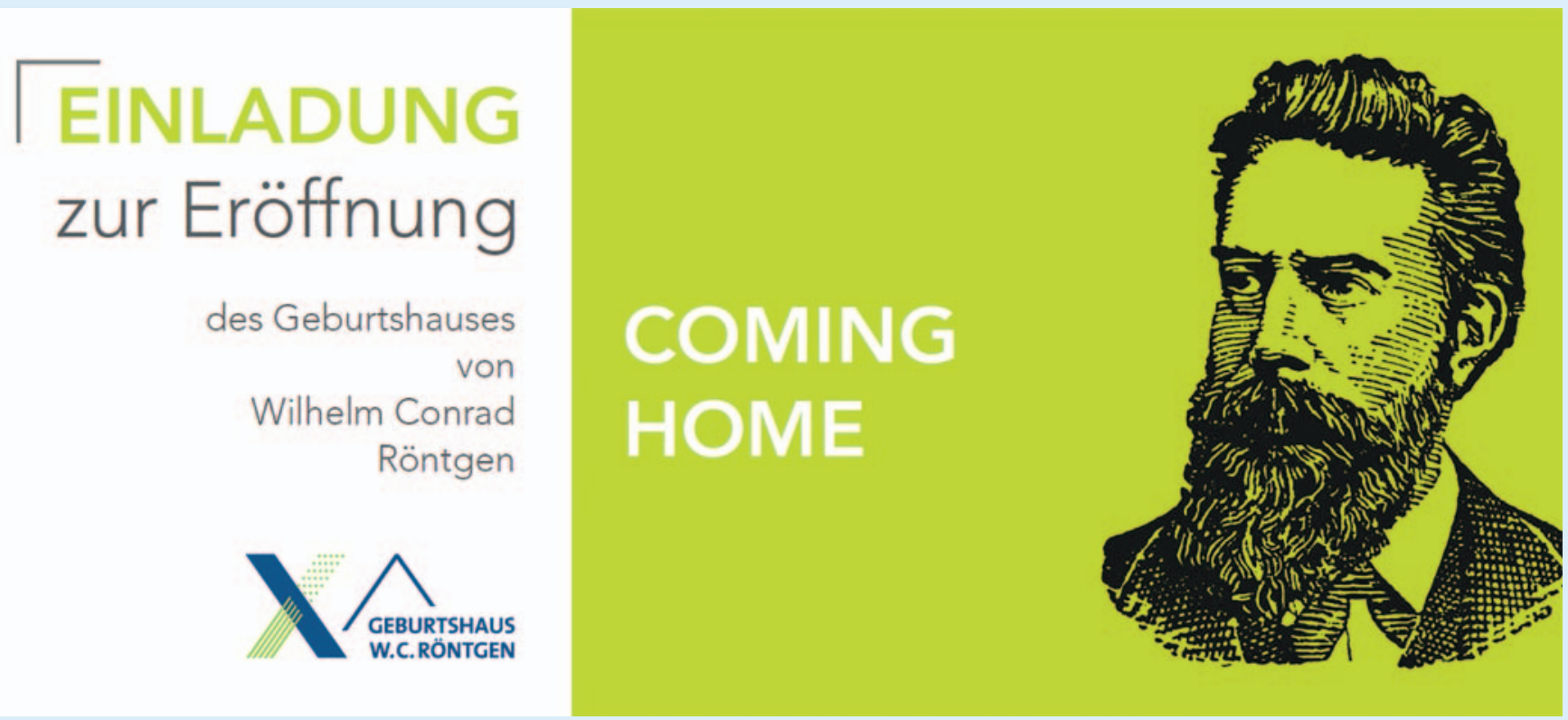

Wir laden Sie herzlich ein, mit uns das Röntgenjahr 2020 einzuläuten - während der Festwoche rund um die Eröffnung des Röntgen-Geburtshauses in Remscheid-Lennep. Alle Veranstaltungen sind öffentlich, kostenlos und Sie brauchen sich nicht anzumelden.

Freitag, 27. März 2020

15.00 Uhr: Feierliche Eröffnung des Geburtshauses von Wilhelm Conrad Röntgen 19.00 Uhr: Geburtstagskonzert der Bergischen Symphoniker im Teo-Otto-Theater

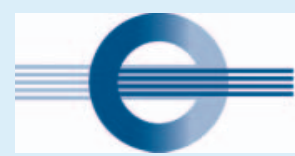

DEUTSCHE RÖNTGENGESELLSCHAFT

Gesellschaft für medizinische Radiologie e.V.

\section{R Ö N T G E N}

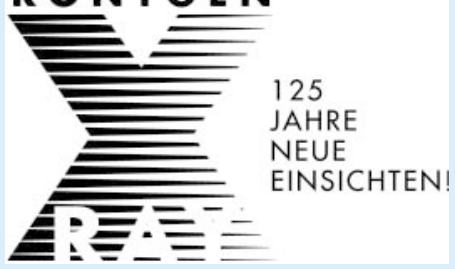

Samstag, 28. März 2020

11.00 Uhr: Verleihung der Röntgen-Plakette im Teo-Otto-Theater

\section{ORTE}

Röntgen-Geburtshaus

Gänsemarkt 1

42897 Remscheid-Lennep

\section{Teo-Otto-Theater}

Konrad-Adenauer-Straße 31-33

42853 Remscheid 